\title{
EL PROCESO INQUISITORIAL CONTRA JUAN DEL RÍO, RACIONERO DE LA CATEDRAL DE TOLEDO'
}

\author{
María del Pilar Rábade ObRadó \\ Universidad San Pablo-CEU
}

\begin{abstract}
SUMARIO
1. Algunos datos biográticos sobre Juan del Río.- 2. La acusación y los testigos del fiscal.- 3. La defensa y los testigos de abono.- 4. ¿Cristianos viejos contra cristianos nuevos?
\end{abstract}

Entre 1487 y 1488 Juan del Río, racionero de la Catedral de Toledo, fue sometido a un proceso inquisitorial que terminó con su condena a la hoguera ${ }^{2}$. En este trabajo se estudia dicho proceso, que aporta algunas claves para profundizar en la situación que vivían los judeoconversos en los momentos finales del siglo XV. cuando el Santo Oficio había iniciado ya su actividad, pero todavía en los momentos previos a la proliferación de los Estatutos de Limpieza de Sangre, en una etapa en la que las relaciones entre cristianos viejos y nuevos estaban ya marcadas por una más que evidente tensión, que tenía consecuencias muy negativas para los que llevaban sangre judía en sus venas, y que se refleja con nitidez en las páginas del proceso que se va a estudiar.

\footnotetext{
'Este trabajo forma parte del Proyecto de Investigación Multidisciplinar de la Universidad Complutense 5686. "Propaganda y legitimación en los orígenes de la Monarquia Hispánica (ca. 1400-cia. 1520: una visión multidisciplinar".

'En el Archivo Histórico Nacional (desde ahora. AIIN). Inquisición de Toledo (desde ahora. IT). Ig. 176. $n^{\prime \prime} 8$.

"Anuario de Istudies Mlediciales". 28 (1998)
} 


\section{Algunos datos biográficos SObRe JuAn del Río}

Son muy escasos los datos biográficos relativos a Juan del Río que ofrece el sumario al que hubo de enfrentarse. Desde luego, lo que parece evidente es que nuestro hombre logró labrarse una cierta posición, que le había llevado. desde su condición de hijo de un herrador ${ }^{3}$, hasta una carrera eclesiástica que, aunque no rayó a la misma altura de las que protagonizaron otros conversos ${ }^{4}$, sí que estuvo marcada por un cierto éxito 5 .

Cuando se inicia su proceso en 1487, hacía ya unos cuatro años que Juan del Río era racionero de la catedral de Toledo, de la que había sido limosnero también durante algún tiempo. Además, estaba en posesión de diversos beneficios eclesiásticos, repartidos por localidades no muy alejadas de la ciudad de Toledo, donde estaba avecindado: Cañete, Corpa y Madrid (en la Iglesia de Santiago), aunque había tenido la desgracia de no poder ocupar ninguno de los tres, pues le habían sido usurpados, respectivamente, por el nuncio Francisco Ortiz y sus parientes, por Mosén Tolosa, criado del Cardenal Pedro González de Mendoza, y por el Cabildo de San Justo de

\footnotetext{
'Así lo manifiesta uno de sus testigos de abono. Juan de Estrada. canónigo de Toledo, que afirma que el padre del acusado era tenido por vizcaíno: en qualquier caso, esto no obsta para que nuestro sacerdote fuera converso, tal como parecen indicar otros datos que se insertan en su proceso. y que muestran a nuestro hombre emparentado con diversos personajes de cuya ascendencia judia no cabe duda. sin olvidar además que Juan del Río en ningún momento de proceso afirma ser cristiano viejo.

${ }^{4}$ Sin pretensiones de exhaustividad, se pueden citar los nombre de algunos cristianos nuevos que llegaron a convertirse en prelados de la Iglesia Católica, y cuyas carreras eclesiásticas son bien conocidas: Pablo de Santa María y Alonso de Cartagena (L. Serrano. Los comversos Dom Pablo de Santa María y Don Alonso de Cartagena. Madrid. 1942): Juan de Torquemada (N. IóPEz MARTÍNEZ y V. PROAÑo GIl. Tractatus contra Madiamitas el ismaelitas de Juan de Torquemada. Burgos. 1957): Juan Arias de Ávila (M. P. RÁBADE OBRADÓ. Una élite de poder enla Corte de los Répes Católicos: los judeocomersos. Madrid. 1993. pp. 101-172).

${ }^{5}$ Ina carrera paralela a las de otros cristianos nuevos. pertenecientes a familias insertas en las oligarquías de las localidades en las que residian. que afianzahan su posición repartiendo sus vástagos entre la correspondiente administración concejil (ver F. MÁRQUEZ VILLANUEVA. Comersos y cargos concejiles en el sigho XV. "Revista de Archivo. Bibliotecas y Museos". 63 (1957). pp. 503-40, y S. HAl.ICZER. The Castiliam Urham Patriciate and the Jewish Expulsiom of 1492. "American Historical Review". 68 (1973). pp. 35-58) y la lglesia local: auncpue esta última cuestión todavía no ha sido estudiada en profundidad. sí que se han analizado los casos concretos de algunas familias: J. HERNÁnDEZ Franco. Trenectoria social de ana familia amiersa: los Samtestera-Lara. Del empinamiento a la condena, en A. MESTRE SANCHis y E Giménez lóplaz (eds.). "Disidencias y exilios en la España Moderna". Alicante. 1997. pp. 179. 92: J. A. Ol.lero PINA. Una familia de comerersos sevillanos én los origenes de la Inquisicioin. los Benadera. "Hispania Sacra". 40 (1988), pp. 45-105
} 
Alcalá de Henares. Igualmente, también estaba en posesión de un préstamo en la Iglesia de San Vicente de Toledo, en este caso sin problemas de usurpación. Finalmente, había ostentado en tiempos pasados una canongía en la catedral de Sigüenza, si bien había sido obligado a renunciarla en favor de un personaje que es identicado por el apellido Savra.

Juan del Río no pertenecía a ninguna de las grandes familias conversas toledanas $^{6}$, y tampoco parecía destacar ni por su espiritualidad ${ }^{7}$ ni por su talento intelectual ${ }^{8}$, así que tuvo que verse apoyado por personas de influencia para afianzar su carrera eclesiástica. Muchas dudas plantea su relación con el Cardenal Mendoza, que muy posiblemente fue su obispo en Sigüenza ${ }^{9}$, y que fue arzobispo de Toledo durante los años en que Juan del Río prestó sus servicios en la catedral de dicha ciudad ${ }^{10}$.

En efecto, las relaciones del sacerdote converso con Mendoza no debieron ser precisamente cordiales, o al menos eso es lo que se da a entender en el proceso; a lo largo del mismo, el encausado afirmaba que entre sus enemigos se contaban algunos clérigos, que "han tratado e tratan comigo pleitos ante la santa sede apostólica por comisyón del señor

\footnotetext{
${ }^{6}$ Los apellidos de las mismas pueden verse en F.J. ARANDA PÉREZ, Judeoconversos y poder municipal en Toledo durante la Edad Moderna: una discriminación poco efectiva, en A Mestre Sanchís y E. Giménez López (eds.), "Disidencias y exilios", pp. 155-168, y en concreto p. 157.

${ }^{7} \mathrm{Algo}$ que se evidencia a partir de la lectura del misno proceso inquisitorial, pues a lo largo de sus páginas el abogado del racionero desgrana sus prácticas cristianas, tratando de apoyar sobre las mismas la inocencia de su defendido. Estas prácticas cristianas nos hablan de una religiosidad centrada en aquellos ritos y ceremonias más frecuentes entre los cristianos de momento, produciendo la impresión de que el cumplimiento de Juan del Río se limitaba a lo que podría considerarse el mínimo imprescindible para un hombre en sus circunstancias.

${ }^{8}$ Aunque tal vez sea una exageración, provocada, más que por la humildad, por el afán de despojar de importancia algunas palabras pronunciadas descuidadamente, el propio Juan del Río afirmaba en un momento de su proceso que es "persona ynfima e sinple, de poco saber", añadiendo pocas páginas después que su simpleza era conocida por clérigos y legos, y que la misma le había acarreado muchas burlas y escarnios, y que muchos consideraran que no era merecedor de la situación en la que se encontraba.

${ }^{9}$ Recuérdese que fue precisamente Mendoza el que le obligó a renunciar su canongía de Sigüenza: Mendoza fue obispo de esta ciudad entre los momentos finales de 1467 y 1473, año en que se convirtió en arzobispo de Sevilla; sobre su actividad al frente de ambas diócesis, ver F.J. Villalaba Ruiz de TOledo, El cardenal Mendoza (1428-1495), Madrid, 1988. Si la hipótesis apuntada es cierta, lo más probable es que Juan del Río fuera ya un hombre de edad avanzada cuando pasó por el amargo trance de un proceso inquisitorial (en sus páginas se le describe como lisiado y quebrado de salud); además, uno de sus testigos de abono, el capellán y canónigo de Toledo Alfonso de Albornoz, que manifiesta conocerle desde hace unos veinte años, sitúa su primer encuentro con Juan del Río en la casa de Mendoza, cuando éste aún era obispo de Sigüenza.

${ }^{10}$ Concretamente, entre 1483 y 1494 , año en que se produjo su fallecimiento.
} 
cardenal". Se quejaba también de que en varias ocasiones se le había tratado de apartar de la iglesia catedral, aunque hasta el momento sin éxito, y aunque esto no se afirma, da la impresión de que Mendoza no era ajeno a esos manejos. Por contra, sus relaciones con Alfonso Carrillo, el antecesor de Mendoza en el arzobispado de Toledo, debieron ser mucho mejores, pues Juan del Río fue procurador de dicho arzobispo en Roma

Quizá, la clave de la posición que consiguió labrarse Juan del Río estuvo en la protección que se le dispensó en la corte papal, donde residió algún tiempo, durante los años de pontificado de Sixto IV". Si es de creer la declaración que efectuó ante los inquisidores, respondiendo a la acusación presentada por el promotor fiscal, en Roma se hizo famoso por su devoción a la Vírgen del Popolo, que, según la tradición, había sido pintada por San Lucas; enterado el pontífice, ordenó al arzobispo de Salerno, su referendario mayor, que lo acogiera en su casa, proporcionándole todo lo que necesitara para vivir. La relación entre el converso y su anfitrión debió de ser muy cordial, pues si Juan del Río dispuso, en vida del prelado, de una renta anual de cincuenta ducados, tras su muerte, y en virtud del correspondiente testamento, pasó a disfrutar de doscientos ducados anuales.

\section{LA ACUSACIÓN Y LOS TESTIGOS DEL FISCAL}

La acusación del promotor fiscal, el bachiller Ruy Sánchez de Madrid ${ }^{12}$, contra Juan del Río se fundamentaba sobre diversos testimonios

\footnotetext{
"Según propia declaración. la estancia de Juan del Río en Roma se prolongó a lo largo de más de seis años, necesariamente entre 1471 y 1484. pues estas dos fechas marcan el inicio y el final del pontificado de Sixto IV.

${ }^{12}$ Se le identifica como escribano público y del número de Toledo y como notario apostólico. Los inquisidores fueron Don Vasco Ramírez de Ribera, obispo de Coria, y el doctor Alfonso Suárez de Fuente el Sauz, que fueron los inquisidores que durante los años en los que se desarrolló el proceso al que nos referimos actuaron contra los vecinos de Toledo y de localidades próximas a dicha ciudad. El primero es identificado en el proceso contra Juam Sánchez de San Pedro (AHN. IT. Ig. 183. n" 18) como protonotario apostólico, arcediano de Talavera y canónigo de Toledo, mientras que el segundo es identificado como chantre de la colegiata de Castrojeriz; por su parte. Don Vasco fue también, según el proceso contra Mencía de la Peña (AHN. IT, Ig. 174. n" 9), vicario general de Toledo. Ambos actuaron como inquisidores, por ejemplo, en los procesos contra el ya citado Juan Sánchez de San Pedro, 14861487: contra Juan de Toledo. 1486-1487 (AHN. IT. Ig. 185, $\mathrm{n}^{\circ}$ 10); contra Juan de la Jara. 1486-87 (AHN, IT, lg. 158, n" 10); contra Alfonso de Alvar Sánchez, 1487-1488 (AHN. IT. lg. 133. n" 8); contra Inés Díaz, 1487-1488 (AHN. IT, Ig. 143. n" 3): contra Leonor Gómez. 1487-1488 (AHN, IT, lg. 152, "10 11); contra María, hija de Alfonso de Alvar Sánchez. 1487-
} 
que contra él se habían recogido; tan sólo uno de ellos hacía alusión a una práctica que, cuando era realizada por un judeoconverso, era considerada como una grave falta contra el cristianismo, y, por tanto, como indicadora del criptojudaísmo del que la había realizado ${ }^{13}$ : concretamente, se acusaba al sacerdote converso de haber comido carne en días vedados por la Iglesia, sin tener necesidad de ello.

Las otras acusaciones que se esgrimieron contra nuestro hombre se referían a opiniones que éste había manifestado, que se consideraba también que, por sí solas, demostraban el criptojudaísmo de quien las emitía ${ }^{14}$. El racionero se había atrevido a realizar algunas afirmaciones que contradecían abiertamente la doctrina católica: había asegurado que la divinidad de Jesucristo había surgido tras su subida a los cielos, pero no antes; había negado la sabiduría y omnipotencia de Cristo, afirmando que no había sabido que Judas lo iba a traicionar; finalmente, de algunas frases por él pronunciadas se deducía que no creía en la virginidad de María.

También fue acusado Juan del Río de mantener opiniones contrarias a la actividad del Santo Oficio, algo que, en opinión de los inquisidores, era igualmente indicativo de la afición que sentía hacia el judaísmo ${ }^{15}$; concretamente, se recogieron los testimonios de algunas personas que habían oído cómo Juan del Río criticaba los castigos que la Inquisición estaba aplicando a los judaizantes, y que también habían escuchado sus blasfemias contra el Santo Oficio. En otras ocasiones, se le había oído decir que los herejes que

1490 (AHN, IT, Ig. 164, n" 10). Sin embargo, en todos estos casos el promotor fiscal fue el bachiller Fernando Rodríguez del Barco, que era capellán de los Reyes Católicos, aunque también se han documentado otros casos en los que ambos inquisidores actuaron juntamente con Ruy Sánchez de Madrid, y entre ellos el proceso contra María de Ribera, 1487-1490, en el que este último se alternó en el oficio de fiscal con el anterior (AHN, IT, lg. 176, $n^{\circ}$ 6), o el proceso contra Mencía Suárez. 1487-1490. en el que actuó en solitario como fiscal el mismo que acusó a nuestro hombre (AHN. IT, lg. 158, n" 25)

${ }^{1:} \mathrm{No}$ se puede soslayar que estamos en un momento en el que la vivencia religiosa se centra en los aspectos más externos y materiales, que son precisamente los que, desde el punto de vista de los inquisidores, marcan la diferencia entre cristianos ortodoxos y heterodoxos; sobre esta cuestion, ver las interesantes reflexiones de J. CONTRERAS, Judios, judaizantes y judeoconversos en la Península Ibérica en los tiempos de la expulsión, en A. AlCaLÁ (ed.), "Judíos. Sefarditas. Conversos. La expulsión de 1492 y sus consecuencias", Valladolid, 1995, pp. 457-477, y más concretamente $\mathrm{pP}$. 464-465.

${ }^{14}$ Consultar M.P. RÁBADE OBRADÓ, Religiosidad y práctica religiosa entre los conversos castellanos (1483-1507), "Boletín de la Real Academia de la Historia", CXCIV-1 (1997), pp 83-142. y específicamente pp. 96-102.

${ }^{15}$ Ver. asímismo, M. P. RÁBADE OBRADÓ. Religiosidad y práctica religiosa, pp. 121-122. 
quemaba la Inquisición, si morían en la Ley de Moisés, eran mártires, pues era mejor ley que la cristiana.

Estas acusaciones fueron formuladas por un grupo bastante amplio de testigos, de la calidad más heterogénea. Entre ellos había desde un eclesiástico, Lope Fernández, que era cura en la parroquia de San Vicente, hasta un judío, Don David de Abendara, pasando por diversos personajes, todos ellos laicos, con los que el sacerdote parecía tener contacto habitual: Rodrigo de Olmos, Isabel Díaz, Bernardo de Palencia... A estos testimonios se unió el del carcelero de la Inquisición, Pedro de Zamora, y, por supuesto, tampoco faltó el de un desafortunado converso, Juan de San Pedro, que también terminó sus días en la hoguera.

No hace falta insistir en la debilidad de la acusación de criptojudaísmo que se lanzó contra Juan del Río, pues lo cierto es que, dejando aparte sus supuestas afirmaciones acerca de la ley de Moisés, no se probó que hubiera realizado ninguna práctica religiosa del judaísmo; eso sí, Juan del Río parecía mantener opiniones que no casaban totalmente con la doctrina católica, si bien estas opiniones, por sí mismas, no significaban que nuestro hombre judaizara, si no que, más bien, demuestran su escasa formación teológica, su desacuerdo con la acción inquisitorial, así como también su incapacidad para mantener la boca cerrada, en un momento en que esto empezaba a ser algo fundamental para los cristianos nuevos.

\section{LA DEFENSA Y LOS TESTIGOS DE ABONO}

Para defenderse de las acusaciones del fiscal, nuestro hombre gozó de la ayuda de Gutierre de Palma ${ }^{16}$ y de Diego Téllez ${ }^{17}$. Lógicamente, en su respuesta a las alegaciones del promotor fiscal Juan del Río negó todas las

\footnotetext{
${ }^{16}$ Tal vez se trate del mismo Gutierre de Palma conocido, precisamente, por ser el autor de una obra en favor de los conversos, redactada tras los sucesos que acontecieron en Toledo andando el año 1449; sobre esta cuestión, ver R. GONZÁLvEZ RUIZ, El bachiller Palma, alutor de una obra desconocida en favor de los comersos, "Simposio Toledo Judaico". 2 vols.. Toledo, 1973, vol. I, pp. 31-48.

${ }^{17}$ Que se destacó con harta frecuencia como defensor de los conversos toledanos encausados por el Santo Oficio; entre otros, defendió a los ya mencionados Mencía de la Peña: María, hija de Alfonso de Alvar Sánchez: María de Ribera... Consiguió. como es lógico, tanto éxitos como fracasos: mientras que Juan del Río acabo en la hoguera. Mencía de la Peña tan sólo fue penitenciada, la hija de Alfonso de Alvar Sánchez fue condenada a cárcel perpetua y María de Ribera fue absuelta.
} 
acusaciones que contra él se habían lanzado. Para neutralizar los testimonios de aquéllos que aseguraban haberle oído realizar aseveraciones contrarias a la doctrina católica, el racionero se defendió afirmando que creía todo lo que "commo symple clérigo soy tenido a creer", haciendo hincapié en el hecho de que no era un hombre docto, añadiendo que si en algún momento había pronunciado palabras de esa índole lo habría hecho llevado por su ignorancia, pero sin ninguna intención de contradecir la doctrina católica.

Tal como solía ser habitual en estos casos, el encausado se defendió de las acusaciones del promotor fiscal esgrimiendo también toda una serie de prácticas cristianas, que pretendían demostrar - por sí solas- su ortodoxia religiosa $^{18}$. Así, Juan del Río insistió en la mucha devoción que sentía hacia la Vírgen María, una devoción que le había ayudado a ser conocido en la corte pontificia durante su estancia en Roma, y que se manifestaba en el rezo de sus Horas.

El sacerdote insistió, igualmente, en una práctica sacramental que se limitaba a confesar y a comulgar "en tienpo devido", recordando asímismo que guardaba tanto los domingos como las otras fiestas que mandaba guardar la iglesia. Recordó aquellas oraciones que solía rezar con más frecuencia: el credo, el padrenuestro, el avemaría, la salveregina...

Igualmente, y también para fundamentar su condición de cristiano leal, el sacerdote recordó a los inquisidores los servicios que en algún momento les había prestado; así, recordó cómo había acudido a declarar ante ellos lo que sabía de Rodrigo de Olmos, con el que había coincidido en Alcalá de Henares, y cómo había animado a la mujer y suegra de Juan de San Pedro, quemado por el Santo Oficio, a declarar contra él. Demostrando que su lealtad al cristianismo era más fuerte que el afecto que guardaba a sus parientes, había empujado a la mujer de uno de sus familiares, Luis de Ayllón, a declarar ante los inquisidores sus prácticas criptojudías.

También insistía Juan del Río en diversas prácticas que, aún no teniendo ningún sentido religioso para los cristianos, permitían marcar diferencias frente a los judíos; así, afirmaba que entre las viandas que consumía habitualmente se contaban el tocino, las perdices, las anguilas, el

\footnotetext{
${ }^{18}$ Sobre esta cuestión, ver M.P. RÁBADE OBRADÓ, Conversos, Inquisición y criptojudaísmo en el Madrid de los Reyes Católicos, "Anales del Instituto de Estudios Madrileños", XXXVI (1996), pp. 249-267, y específicamente 264-265; por otra parte, cierto es también que los inquisidores parecían entender la religión desde una óptica puramente material, mostrando habitualmente un escaso interés por las creencias más íntimas de los encausados (consultar M. P. RÁBADE OBRADÓ, Religiosidad y práctica religiosa, pp. 96-97.
} 
congrio y el conejo, todas ellas prohibidas para los judíos, señalando igualmente que consumía gallinas muertas al modo cristiano, cuyo consumo estaba también prohibido a los judíos.

Finalmente, el converso achacaba las acusaciones que contra él se habían recogido a la envidia que hacia él sentían muchos, al deseo de apoderarse de sus beneficios que tenían otros, en suma, a los muchos enemigos que tenía, deseando todos ellos su perdición. Entre esos enemigos destacaba de forma especial a algunos clérigos, que, precisamente por serlo, estaban en mejores circunstancias para hacerle daño.

Entre los testigos de abono que señaló Juan del Río para que ratificaran su condición de cristiano sincero se contaron casi exclusivamente eclesiásticos, alguno de ellos de tanta relevancia como el maestrescuela de la catedral, el doctor Francisco Álvarez de Toledo, también converso, y una de las figuras más destacadas en la historia de la sede toledana durante las postrimerías del siglo $\mathrm{XV}$ y los inicios de la siguiente centuria ${ }^{19}$. Entre sus testigos de abono se contaron, igualmente, eclesiásticos vinculados con la catedral toledana, como el canónigo y capellán Alfonso de Albornoz, o el también canónigo Juan de Estrada.

En líneas generales, sus testigos de abono no ayudaron excesivamente a Juan del Río, pues contestaron al interrogatorio propuesto por éste de forma sumamente vaga, mostrando, bien su desconocimiento de lo que se les preguntaba, bien su desinterés hacia la suerte del reo. En algunos casos, manifestaron la poca estima que hacia él sentían, como el maestrescuela, que le tachó de hombre liviano y escandaloso; en otros, admitieron la veracidad de algunas de las acusaciones que se imputaban al converso: por ejemplo, el clérigo Andrés de Toledo recordó haberle oido decir en una ocasión que la Inquisición se hacía por las haciendas de los cristianos nuevos, aunque este testigo también recordaba haberle oído alabar al Santo Oficio, y además le tenía por cristiano, pues le había visto realizar muchas obras de tal.

Como era también habitual, Juan del Río presentó en su defensa un pliego de tachas, a través del cual trataba de eliminar los posibles testimonios de sus enemigos; entre ellos, cita nada menos que a uno de sus jueces, el obispo de Coria, al que había hecho algunos deservicios mientras ambos se encontraban en Roma.

\footnotetext{
${ }^{19}$ Sobre esta cuestión, consultar M.P. RÁBADE OBRadó, Una élite de poder. pp. 47 y ss.
} 
Pero no era el único personaje poderoso que se contaba entre sus enemigos, pues entre ellos también estaba el nuncio Francisco Ortiz, así como sus parientes y criados (algunos aparecen citados por sus nombres, concretamente aquéllos con los que la enemistad había sido más manifiesta), debido a la lucha por la posesión del beneficio que Juan del Río tenía en Cañete, episodio en el que por cierto, el nuncio y don Vasco unieron sus fuerzas frente al desafortunado sacerdote, pues cuando éste, ofuscado, acusó al nuncio de enriquecerse a costa de la Iglesia y de otras cosas similares, ambos lograron meterle en la cárcel arzobispal, aunque al fin fue liberado.

Entre sus enemigos no sólo se contaban personas poderosas, si no que había también algunas humildes, aunque susceptibles de hacerle mucho daño; es el caso de Juan de San Pedro, quemado por el Santo Oficio, pues el eclesiástico había convencido a su mujer y a su suegra para que testificaran contra él. Por si eso fuera poco los tocayos habían tenido numerosas pendencias, atizadas por los celos del laico, que creía que su mujer se entendía con el sacerdote. Las sospechas de éste sobre un posible falso testimonio de San Pedro se habían visto atizadas por otro preso de la Inquisición, Rodrigo Jarada, al que aquél había reconocido haber dicho algunas cosas no porque fueran ciertas, si no porque le apretaba don Vasco.

En otros casos, los enemigos tachados por el sacerdote converso son aquéllos que le habían despojado de algunos de sus beneficios, o que trataban de despojarle de ellos. Como Alonso Sánchez, capellán de coro de la catedral, que deseaba apoderarse de su ración, algo que había intentado primero con dádivas y halagos, después con amenazas, o como Mosén Tolosa, muy bien relacionado con Mendoza, que le tenía ocupado el curato de Corpa, o como el canónigo de Sigüenza Savra, al que también se ha aludido más arriba. También se puede incluir entre éstos a Diego Rangel, que había sido su compañero en la procuración de Alonso Carrillo en Roma, y que había hecho todo lo posible por enemistarle con personajes poderosos, buscando, por esa vía, su propio medro.

Finalmente, también señala los nombres de algunos enemigos, que pudieron levantarle falsos testimonios por problemas de otra índole, aunque fundamentalmente económicos; entre ellos, Juan de Toledo y sus hijas, o un hombre cuyo nombre no se especifica, aunque se le identifica como el cojo que sirvió durante algún tiempo al cura de San Juan, que también era racionero en la catedral. 
Aunque Juan del Río acertó en algunas de sus tachas, señalando a personas que, efectivamente, habían testificado contra él ${ }^{20}$, los inquisidores consideraron que ninguna acreditaba enemistad suficiente de los tachados hacia el reo, así que fueron desestimadas.

\section{4. ¿CRISTIANOS VIEJOS CONTRA CRISTIANOS NUEVOS?}

El examen del proceso contra Juan del Río no deja excesivo lugar a la duda: los inquisidores actuaron con rigor extremo, condenando al acusado a la hoguera sobre la base de testimonios bastante lábiles. La pregunta se hace inevitable: ¿por qué actuaron los inquisidores con tanto rigor?. Aunque es difícil responder a este interrogante, se puede aventurar que la ascendencia judía de Juan del Río y su condición de sacerdote, y además de sacerdote poseedor de diversos beneficios eclesiásticos, pudo tener consecuencias letales para nuestro hombre.

No hace falta recordar aquí la escalada de hostilidad a la que se habían tenido que enfrentar los judeoconversos toledanos a lo largo del siglo $\mathrm{XV}$, trufada de acontecimientos tan luctuosos como los tumultos de $1449 \mathrm{y}$ $1467^{21}$. Una hostilidad que encontró un cauce de expresión legal cuando empezó a actuar en Toledo un tribunal inquisitorial que, destinado a perseguir la herejía en todo el territorio de la archidiócesis de Toledo, se empleó a fondo con los judeoconversos que estaban avecindados en esta ciudad $^{22}$.

\footnotetext{
${ }^{20}$ Por ejemplo, Alonso Durazno. Según Juan del Río, aparte de ser apaniaguado de Don Vasco, era hombre deshonesto, y por tal le había denunciado el sacerdote mientras era sacristán de Santa Justa, consiguiendo que fuera despedido de dicho oficio; también le había denunciado el sacerdote por un robo que había cometido en casa del joyero Alfonso de Toledo, que, siendo reconciliado, no se había atrevido a actuar contra él. Bien es cierto que el testimonio de Durazno era de escasa relevancia, aunque muy mal intencionado, pues afirmaba haber visto a sacerdote comer carne en un día vedado por la Iglesia, aunque añadiendo que éste le había dicho que lo hacía con licencia.

${ }^{21}$ Sobre los mismos, ver E. BEnito RUANo, Toledo en el siglo XV, Madrid, 1961, y también Los orígenes del problema converso. Barcelona, 1976, así como N. RoTH, Anticonverso Riots of the Fifteenth Century. Pulgar and the Inquisition, "En la España Medieval", 15 (1992), pp. 367-394, sin soslayar las páginas que a esta cuestión dedica B. NETANyAHu, The Origins of the Spanish Inquisition, Nueva York, 1995.

${ }^{22}$ Tal como muestra la rica información - aunque desgraciadamente muy restringida en el tiempo- que suministran F. CANTERA BURGOS y P. LEÓN TELLO, Judaizantes del Arzobispado de Toledo habilitados por la Inquisición en 1497 y 1497, Madrid, 1969. Bien es verdad que también es cierto que a partir del año 1495 la actividad del tribunal inquisitorial de Toledo
} 
Desde el momento en que la Inquisición se instaló en Toledo, los judeoconversos se vieron inmersos en unas circunstancias absolutamente nuevas para ellos; entre otras cosas, tuvieron que aprender a vivir con el miedo que les inspiraba el Santo Oficio. Efectivamente, a lo largo de las páginas del proceso al que fue sometido Juan del Río se refleja el miedo que sentía hacia la Inquisición, un miedo que, sin ningún lugar a dudas, era compartido por otros muchos cristianos nuevos; un miedo que no sólo tenían aquéllos que judaizaban ${ }^{23}$, pues era compartido por todos los que temían que les levantaran falsos testimonios, unos falsos testimonios que podían llegar a tener muy negativas consecuencias.

La situación de inseguridad en la que vivía Juan del Río, en la que vivían los judeoconversos, se hace patente en la cruda broma que el sacerdote tuvo que soportar en una ocasión durante el día de los Santos Inocentes, cuando el capellán de coro Alonso Sánchez hizo que unos servidores del fiscal de la Inquisición se acercaran a él en lugar público, "disiendo que los padres le mandavan prender, e le llevaron hasta la cárçel del arçobispo, asy dando boses, que le prendían por ereje".

Es evidente que el sacerdote temía que sus enemigos, muy numerosos, recurrieran a los falsos testimonios para buscarle la perdición, tal como confesó al clérigo Andrés de Toledo, uno de sus testigos de abono, al que expresó en alguna ocasión estos temores. Además, Andrés recordaba la existencia de una carta que le había llegado de Córdoba, en la que se le pedía que hiciera relación de los beneficios que tenía su amigo, aunque no lo hizo porque "non era persona que le dañase". Otro de sus testigos de abono, Diego Gómez, sacristán en Santa Justa, recordaba que oyó decir que los herejes que llevaban a quemar ya habían advertido al sacerdote "que se pusiese a cobro", como también recordaba que otros beneficiados "fasían escarnio del dicho Juan del Río, porque sabía tan poco e tenía tanta renta". Una vez preso por el Santo Oficio, a Juan del Río no le quedó ninguna duda, y el carcelero Pedro de Zamora le oyó clamar contra la Inquisición, y afirmar que le habían prendido por tomarle sus beneficios.

decayó de forma considerable, de modo que los datos que se suministran en este trabajo adquieren todavía mayor importancia.

${ }^{23}$ Como ha indicado E. Benito Ruano, De la alteridad en la Historia, Madrid, 1988, pg. 88, la gestión del Santo Oficio, "al prodigarse sobre la generalidad masiva de la población conversa, somete indiscriminadamente a la inquietud y a la inseguridad, anímicas y civiles, tanto a falsos como a verdaderos convertidos". 
El sacerdote converso se sentía víctima de una cospiración, en la que habrían participado los mismos inquisidores, pues no en balde el canónigo Pedro de Vargas, mientras estaba un día en el retrete de la iglesia catedral, había oído la conversación que mantenía un clérigo, hijo de un tal Encinas, notario del Santo Oficio, con otro compañero, afirmando que "agora an de prender a Juan del Río los padres", añadiendo que él obtendría el préstamo de San Vicente y el promotor fiscal se quedaría con su ración.

¿Realmente existió esta conspiración?. Se trata de otra pregunta de difícil respuesta, aunque sí es cierto que algunos indicios apuntan claramente en ese sentido; además, puede contemplarse este episodio como una muestra de la sorda campaña que ya se estaba realizando en ese momento contra los beneficiados de ascendencia hebrea, una sorda campaña que concluiría con la imposición del estatuto de limpieza de sangre en la catedral toledana ${ }^{24}$, en un momento en el que ya es más que evidente la tendencia a la discriminación social de los judeoconversos, con la consiguiente valoración de la "limpieza" como elemento social básico y la escisión entre cristianos viejos y cristianos nuevos ${ }^{25}$.

\section{RÉSUMÉ}

Entre 1487 et 1488, Juan del Río, prébendier de la Cathédrale de Tolède, fut soumis à un procès inquisitorial qui termina par sa condamnation au bûcher. Dans ce travail, on étudie ce procès, qui fournit certaines clefs permettant d'acquerir une connaissance plus approfondie de la situation que traversaient les juifs convertis à la fin du XVe siècle, quand le Saint-Office avait déjà debuté ses activités mais encore à une époque préalable à la proliferation des estatuts de pureté de dans, et de refléter ainsi la forte tension qui existait à cette époque entre les vieux chrétiens et les nouveaux chrétiens.

\footnotetext{
${ }^{24}$ Impuesto en 1547, estaba destinado a tener gran trascendencia. Sobre el mismo existe una abundante bibliografía, pudiéndose destacar las muy acertadas reflexiones que le dedican $\mathrm{A}$. Domínguez ORTIz, Los judeoconversos en España y América, Madrid, 1971, pp. 96 y ss., así como J. CARo BAROJa, Los judios en la España Moderna y Comtemporánea, 3 vols., Madrid, 1978, pp. 294 y ss., vol. II. Años después, fue promulgado en Toledo otro estatuto, en este caso destinado a poner las cosas en su lugar en el ayuntamiento de la ciudad, completando la discriminación en las esferas eclesiásticas con la discriminación en las esferas municipales; a este último estatuto se refiere F. J. ARANDA PÉREZ, Judeoconversos y poder municipal, p. 166.

${ }^{25}$ J.I. GUTIÉRREZ NIETO, La estructura castizo-estamental de la sociedad castellana en el siglo XVI, "Hispania", 125 (1973), pp. 519-563, y concretamente pp. 540 y ss.
} 


\section{SUMMARY}

Between 1487 and 1488. Juan del Río, prebendary of de Toledo Cathedral, was subjected to an inquisitorial process that ended in his being sentenced to burn at the stake. This paper studies thar process, which provides some keys for delving into the situation experienced by converted jews in the dying days of th XVth century, when the Spanish Inquisition had already started its activity. hut still in the days before the proliferation of purity of blood statutes. thus reflecting the heavy tension existing beteen old and new christians in those years. 